\title{
Better Decisions with Airport Management: The Limited Traffic Zone Activation
}

\author{
Francesca Pagliara ${ }^{1, *}$, Pasquale Scialla ${ }^{1}$, Claudio Troisi ${ }^{2}$ \\ ${ }^{1}$ Department of Civil, Architectural and Environmental Engineering, University of Naples Federico II, Italy \\ ${ }^{2}$ Department of Architecture, University of Naples Federico II, Italy
}

Copyright $\bigcirc 2019$ by authors, all rights reserved. Authors agree that this article remains permanently open access under the terms of the Creative Commons Attribution License 4.0 International License

\begin{abstract}
Airport Management is fundamental to support and enhance airport operations from landside to airside, from landing to take off. In this respect, the question to improve the access to an airport infrastructure becomes a crucial point to be investigated. Indeed the objective of this manuscript is to analyse the impacts on road mobility in the forecourt area of Capodichino airport in Naples in Italy, connected with the Limited Traffic Zone (LTZ) activation. In order to evaluate such impacts two scenarios have been proposed and simulated which reproduce, in the peak period 7.45-8.45, the situation in the forecourt area. They are respectively the scenarios before and after the LTZ activation. Microsimulation models have been useful in order to evaluate these effects. In the light of the results obtained, it has been possible to state that the activation of the LTZ will contribute to the improvement of road mobility in the area. This will provide benefits to the users reaching the terminal.
\end{abstract}

Keywords Airport Management, Limited Traffic Zone, Microsimulation, Capodichino Airport

\section{Introduction}

Airport accessibility is becoming more and more an important criterion for airport choice and therefore also for an airport competition. When users choose an itinerary, they think about the transport chain from an origin to a destination. Therefore, the variables having an impact on their decision for a given alternative go beyond the price and quality of air services from one airport to another. The decision for or against a given air service and a given airport is to a certain extent dependent on the accessibility of the airport. Managing airport accessibility, through extra roads, better public transport, new high-speed rail connections, represents a real challenge and it is an important issue from a policy point of view. Most airports are located close to large cities or metropolitan areas $[1 ; 2$;
3]. As a result of the increase in traffic, congestion is becoming a major issue and hence, the accessibility (and the competitive position) to the airport. Improving the accessibility of the airport could be a challenge for policy makers also in terms of the subsequent socioeconomic benefits for the region served.

Ground accessibility to airports plays a dominant role as demonstrated in the work by Skinner [4]. A series of models were calibrated using a air passenger survey data. These models were related to the probability that a given airport was selected based on ground accessibility measures associated with each available airport. A variety of measures for ground accessibility were tested and they turned out to be significant and dominant ones.

Evaluating airports from the perspective of their management or operational efficiency is very important. Air carriers aim at scheduling and locating at airports that are more efficient. On the other hand, municipalities look for airports to be as efficient, and, thus, as competitive as possible to attract business and passengers, and to show local governments that they provide good service [5]. Making easy the access to a given airport represents an important managerial and operations issue which focus on the productivity and efficiency of an airport.

Capodichino Airport, in the south of Italy, is the international airport serving the city of Naples. It is located $5.9 \mathrm{~km}$ north-northeast of the city in the Capodichino district. The airport has two terminal buildings: Terminal 1 is for scheduled flights, while Terminal 2 is used for charter operations.

Naples metropolitan area, with a population of nearly three millions of inhabitants, is the largest of Europe which does not serve as a hub nor secondary hub of any airline [6; 7].

Capodichino is easily accessible thanks to the exit of the so-called "Tangenziale", an urban highway (A56) connecting the city of Naples to the metropolitan area and the highways to Rome (A1), Salerno (A3) and Bari (A16). Fixed taxi rates are in use for the main destinations within the city borders. Moreover the bus line 3S and Alibus 
connect the airport to Garibaldi central station and to Municipio square in the city centre. The distance of the airport to the centre city is about $7 \mathrm{~km}$.

By forecourt it is meant a set of parking areas destinated to drop-off and pick-up passengers arriving and departing from the terminal and their luggage. In the case study of Capodichino airport the forecourt is highlighted in red in Fig.1.

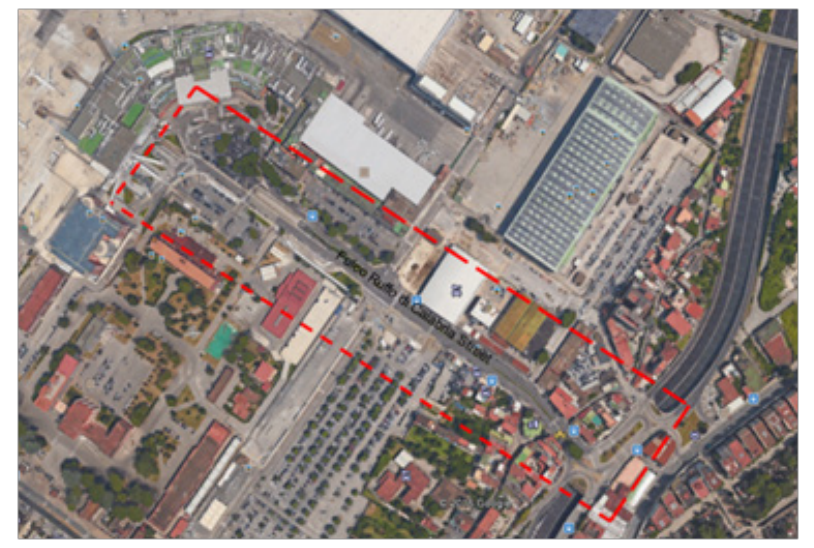

Figure 1. Study area (highlighted in red)

In this area the Italian Civil Aviation Authority (ENAC) has introduced, in collaboration with the municipality of
Naples and the company GE.SA.C., the group managing the area, a Limited Traffic Zone (LTZ) following the law no. 33 of the 22nd of March 2012. The LTZ is an area which is made up of lanes within which the access and the time stay for cars are constrained. The access time stay constraints are indicated by road signals, whose control is made through electronic devices that are approved for operation, in a completely automated way. Anyone who violates these constraints is subject to an administrative sanction.

The LTZ activated in the forecourt area of Capodichino airport, named "Kiss and Ride", allows passengers, and/or those accompanying them, to transit for 10 minutes with their cars in the areas closer to Terminal 1 and to park in specific stalls identified by horizontal and vertical signals, having the logo with the words "Kiss and Ride" in order to make the drop-off and pick-up operations without parking the car.

Those who would stay longer will be able to access one of the parking spaces adjacent to the arrivals/departures Terminal, where some fare policies have been introduced in order to push users to use them.

In Fig. 2 the distribution of car parks in the airport area is reported. Moreover the path of the LTZ and the access gates area are also highlighted in dark grey.

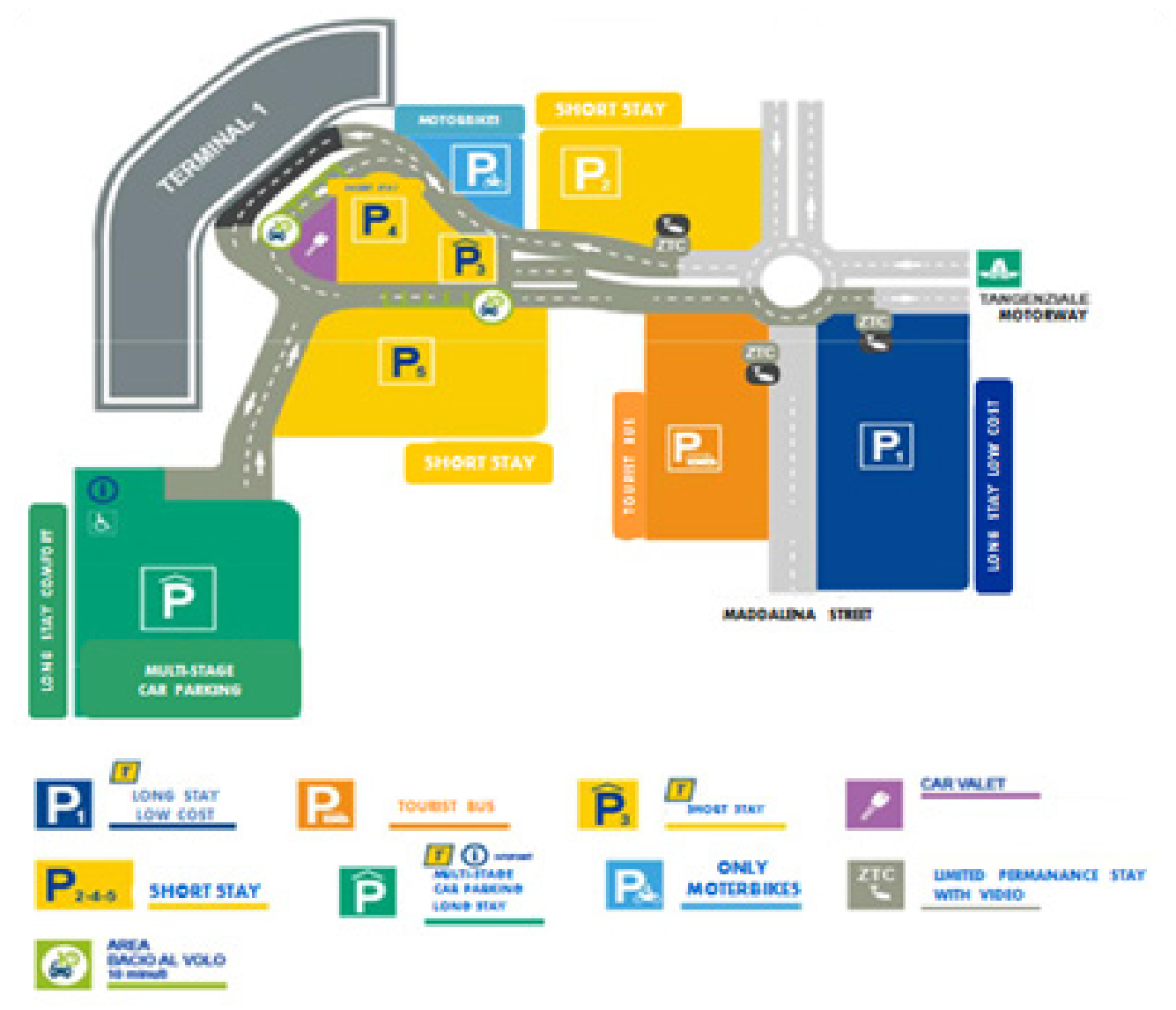

Figure 2. Distribution of car parks and the path destinated to the LTZ 
This paper is organised as follows. In section 2 the methodology is proposed in order to evaluate the impacts of the LTZ activation on road mobility in the Capodichino forecourt area. Section 3 deals with the microsimulation results. In section 4 conclusions are reported.

\section{The Methodology}

Traffic simulation models area mathematical tools able to provide a quantitative representation of traffic flows [8]. These can be classified in three categories: macroscopic, based on the assumption that the behavior of traffic flow can be compared to that of a fluid. The equations are the same of the hydrodynamics. Mesoscopic models simulating the behavior of a group of users having the same behavior, for example a group of users departing from the same origin zone and travelling for the same purpose. Microscopic models simulating the behavior of the single user and comparing it with that of the others [9]. A microsimulation model specification has been here proposed. The first step has been that of the identification of the study area, which coincides with the forecourt area of the Capodichino airport (see the above Fig.1). The second one has been the collection of data, provided by the company GE.SA.C. S.p.A. - Gestione Servizi Aeroporti Campani. The latter was established in 1980 as a majority state-owned enterprise on the initiative of the city of Naples, the province of Naples and Alitalia (whose stake was subsequently acquired by the SEA Group of Milan). GE.SA.C. S.p.A. carried out two surveys in the Capodichino forecourt area, which allowed the description of the forecourt situation before the LTZ activation. The surveys were made through the license plate method by indentifying the cars passing through the LTZ area and by classifying the different categories of the vehicles within the area itself.

The information obtained are:

- the time stay of the vehicles in the forecourt area;

- the $\mathrm{O} / \mathrm{D}$ (Origin-Destination) matrices for the trips internal to the forecourt.

Subsequently, the microsimulation model representing the two scenarios has been implemented by using the S-PARAMICS micro-simulation software.

\subsection{Scenario before the LTZ Activation}

The first step for the construction of the supply model has been the identification of the zones representing the origin and destination of the trips to and from Capodichino airport (see Fig.3).

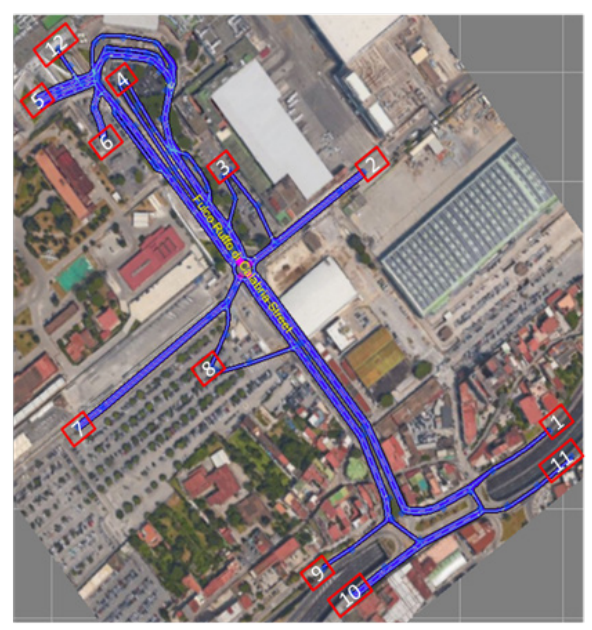

Figure 3. Scenario BEFORE the LTZ activation

Specifically, we have:

- Zone 1 from the motorway and the Tangenziale respectively;

- Zones 9-11 represent the destination of the trips for vehicles leaving the zone and continuing their trips to the Naples tangenziale and the motorway respectively;

- Zone 7 represents the origin and destination zone of the trips for the vehicles entering and leaving the area from Comandante Umberto Maddalena road;

- Zone 2 represents the origin and destination zone of the trips for the vehicles entering and leaving the zone from the US Navy;

- Zone 12 represents the taxi parking at arrival terminal service;

- Zone 3 represents the car park P2;

- Zone 4 represents the car park P3;

- Zone 5 represents the multi-stage car parking;

- Zone 6 represents the car park P5;

- Zone 8 represents the car park P1.

The second step has been that of setting the nodes, which have been positioned in order to allow any change in the geometric and functional characteristics of the network. These are the change of the number of lanes between a link and the subsequent one; the creation of a lane dedicated to public transport; the possibility of modelling the intersections within the study area.

In the third step, the network has been completed through the introduction of the links The latter have been classified in different topological categories and for each of them, the travel speed limits, the width and the number of lanes have been assigned. In Fig. 3, the supply model for the before LTZ activation scenario is reported. 
For the demand data, the survey results supplied by GE.SA.C., containing the $\mathrm{O} / \mathrm{D}$ matrices of the trips internal to the forecourt study area, relative to the peak period 7.45-8.45, have been used.

These matrices take into account all the vehicles categories, i.e. CAR, TAXI, BUS.

\subsection{Scenario after the LTZ Activation}

The supply model in the scenario with the LTZ activation is the same of the before one, since the supply model, after the LTZ introduction, has not experienced any change. The only one concerns the construction, along Fulco Ruffo di Calabria street, on the arrival side terminal, of a stop of the service bus Alibus, which connects Capodichino airport to the city centre.

For the construction of the microsimulation model, two assumptions have been made:

1. rigid mobility demand [10];

2. the vehicles remaining within the forecourt area for a time greater 10 minutes should go to the parking spaces.

From the surveys relative to the travel times for the cars remaining within the forecourt area, (see Table 1), we get that $34 \%$ of them stay within this area for a time greater than 10 minutes, the estimated number of cars is 180 .

Table 1. Car Time spent in the forecourt area

\begin{tabular}{|c|c|c|}
\hline $\begin{array}{c}\text { TIME } \\
\text { STAY: } \\
\text { 10 minutes }\end{array}$ & $\begin{array}{c}\text { \% VEHICLES WITH } \\
\text { RESPECT TO THE } \\
\text { TOTAL }\end{array}$ & $\begin{array}{c}\text { \% VEHICLES ON THE } \\
\text { CUMULATIVE }\end{array}$ \\
\hline $0-10$ & $66.10 \%$ & $66.00 \%$ \\
\hline $11-20$ & $7.60 \%$ & $74.00 \%$ \\
\hline $21-30$ & $6,08 \%$ & $80.00 \%$ \\
\hline $31-40$ & $3.85 \%$ & $84.00 \%$ \\
\hline $41-50$ & $3.04 \%$ & $87.00 \%$ \\
\hline $51-60$ & $2.06 \%$ & $89.00 \%$ \\
\hline $61-70$ & $1.97 \%$ & $91.00 \%$ \\
\hline $71-80$ & $1.07 \%$ & $92.00 \%$ \\
\hline $81-90$ & $0.81 \%$ & $93.00 \%$ \\
\hline$>90$ & $7.42 \%$ & $100.00 \%$ \\
\hline
\end{tabular}

Moreover, the arrival distribution of CARS to the parking spaces has been considered within the period $7.45-8.45$, by subdividing it in 5 minutes intervals. The assumption is that the arrival law follows the Poisson random variable with a parameter value $\lambda$ equal to 5 and that the vehicle stay time within the parking is consistent with the survey (see Fig. 4). Therefore the two scenarios have been implemented within the time-period 7.45-8.45.

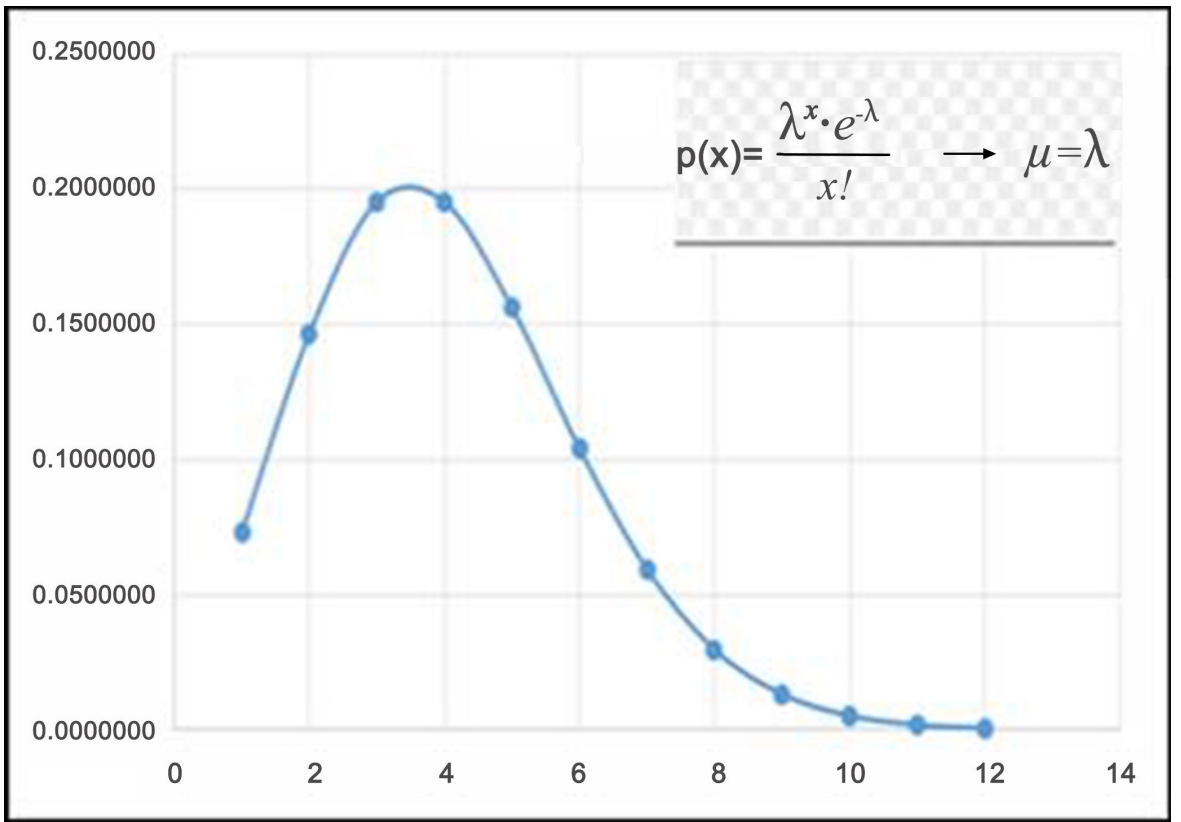

Figure 4. Poisson distribution with $\lambda=5$ 


\section{Microsimulation Results and Discussion}

The results of the microsimulation have allowed computing some indicators, i.e.:

- the queue length.

This indicator has been computed taking into account two routes, i.e. "Queue route 1" and "Queue route 2", which comprise, respectively, the links from the beginning of Fulco Ruffo di Calabria street and the end of the street where the drop-off operations take place (length equal to $550 \mathrm{~m}$ ) and the links starting from Fulco Ruffo di Calabria street and the end of the link where the pick-up operations take place (length equal to $700 \mathrm{~m}$ ). These routes are highlighted in Figures 5 and 6.

- The travel time.

This indicator has been computed taking into account the path indicated with "Journey Path", along which the LTZ has been activated (see Fig. 7).

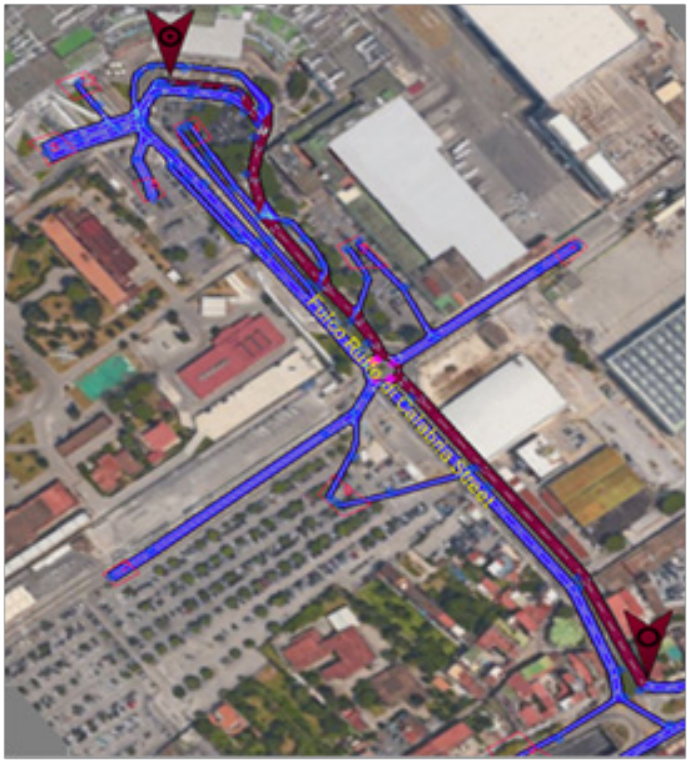

Figure 5. Route "Queue route 1"

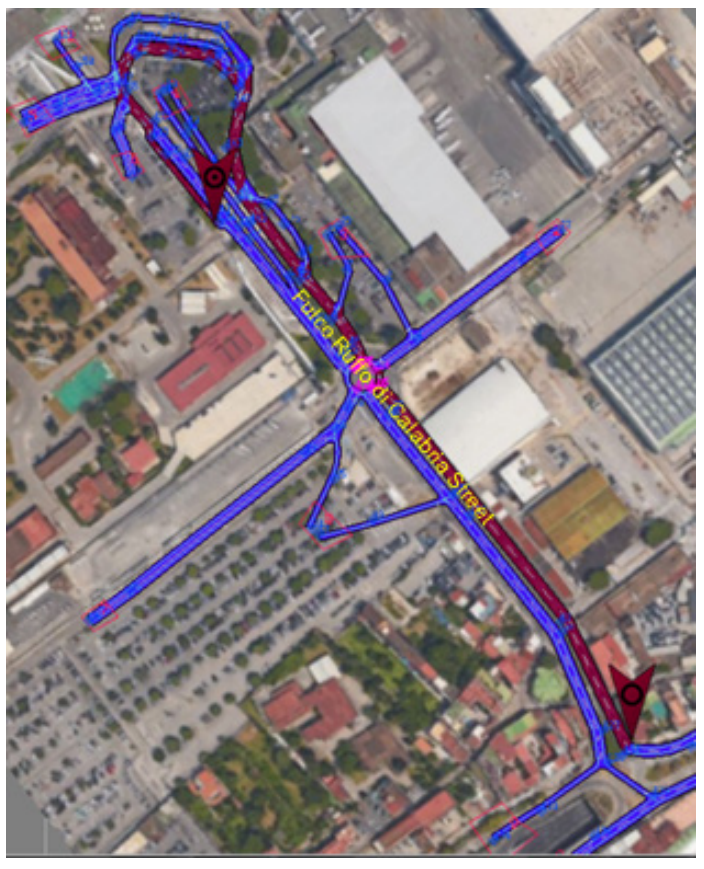

Figure 6. Route "Queue route 2"

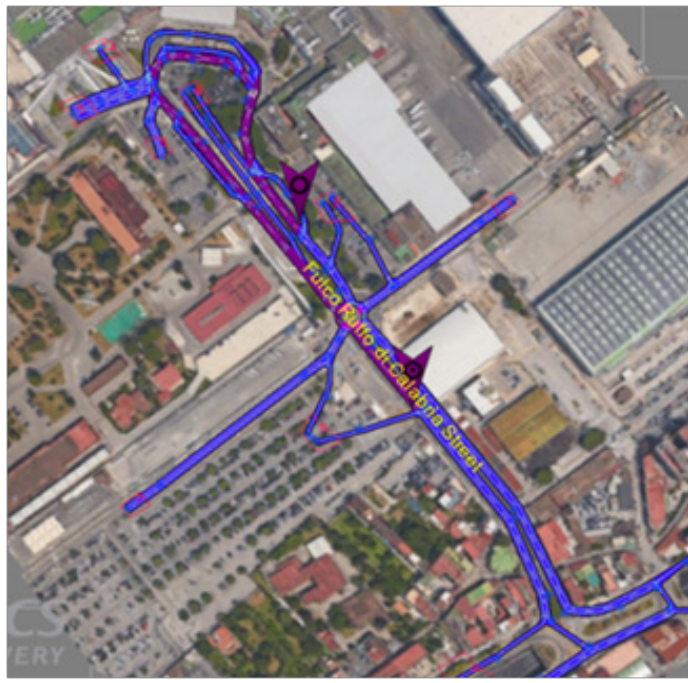

Figure 7. Path "Journey Path"

Results for the Scenario Before the LTZ activation

Table 2. Queue length on the route "Queue route 1"

\begin{tabular}{|c|c|c|c|}
\hline From Time & To Time & Route Name & Maximum Length (m) \\
\hline $07: 45: 00$ & $07: 55: 00$ & Queue Route 1 & 38.39 \\
\hline $07: 55: 00$ & $08: 05: 00$ & Queue Route 1 & 63.04 \\
\hline $08: 05: 00$ & $08: 15: 00$ & Queue Route 1 & 95.71 \\
\hline $08: 15: 00$ & $08: 25: 00$ & Queue Route 1 & 150.73 \\
\hline $08: 25: 00$ & $08: 35: 00$ & Queue Route 1 & 180.82 \\
\hline $08: 35: 00$ & $08: 45: 00$ & Queue Route 1 & 225.61 \\
\hline
\end{tabular}


Table 3. Queue length on the route "Queue route 2"

\begin{tabular}{|c|c|c|c|}
\hline From Time & To Time & Route Name & Maximum Length (m) \\
\hline $07: 45: 00$ & $07: 55: 00$ & Queue Route 2 & 34.89 \\
\hline $07: 55: 00$ & $08: 05: 00$ & Queue Route 2 & 34.50 \\
\hline $08: 05: 00$ & $08: 15: 00$ & Queue Route 2 & 48.89 \\
\hline $08: 15: 00$ & $08: 25: 00$ & Queue Route 2 & 76.36 \\
\hline $08: 25: 00$ & $08: 35: 00$ & Queue Route 2 & 78.04 \\
\hline $08: 35: 00$ & $08: 45: 00$ & Queue Route 2 & 86.95 \\
\hline
\end{tabular}

Table 4. Transit time on the path "Journey Path"

\begin{tabular}{|c|c|c|c|}
\hline From Time & To Time & Path Name & Maximum Journey Time (m) \\
\hline $07: 45: 00$ & $07: 55: 00$ & Journey Path & 1.74 \\
\hline $07: 55: 00$ & $08: 05: 00$ & Journey Path & 3.19 \\
\hline $08: 05: 00$ & $08: 15: 00$ & Journey Path & 5.00 \\
\hline $08: 15: 00$ & $08: 25: 00$ & Journey Path & 6.20 \\
\hline $08: 25: 00$ & $08: 35: 00$ & Journey Path & 7.51 \\
\hline $08: 35: 00$ & $08: 45: 00$ & Journey Path & \\
\hline
\end{tabular}

Results for the Scenario After the LTZ activation

Table 5. Queue Length on the route "Queue route 1"

\begin{tabular}{|c|c|c|c|}
\hline From Time & To Time & Route Name & Maximum Length (m) \\
\hline $07: 45: 00$ & $07: 55: 00$ & Queue Route 1 & 10.58 \\
\hline $07: 55: 00$ & $08: 05: 00$ & Queue Route 1 & 36.81 \\
\hline $08: 05: 00$ & $08: 15: 00$ & Queue Route 1 & 52.80 \\
\hline $08: 15: 00$ & $08: 25: 00$ & Queue Route 1 & 58.52 \\
\hline $08: 25: 00$ & $08: 35: 00$ & Queue Route 1 & 60.50 \\
\hline $08: 35: 00$ & $08: 45: 00$ & Queue Route 1 & 66.87 \\
\hline
\end{tabular}

Table 6. Queue length on the route "Queue route 2"

\begin{tabular}{|c|c|c|c|}
\hline From Time & To Time) & Route Name & Maximum Length (m) \\
\hline $07: 45: 00$ & $07: 55: 00$ & Queue Route 2 & 12.36 \\
\hline $07: 55: 00$ & $08: 05: 00$ & Queue Route 2 & 29.65 \\
\hline $08: 05: 00$ & $08: 15: 00$ & Queue Route 2 & 36.71 \\
\hline $08: 15: 00$ & $08: 25: 00$ & Queue Route 2 & 44.48 \\
\hline $08: 25: 00$ & $08: 35: 00$ & Queue Route 2 & 35.86 \\
\hline $08: 35: 00$ & $08: 45: 00$ & Queue Route 2 & 32.90 \\
\hline
\end{tabular}

Table 7. Transit time on the path "Journey Path"

\begin{tabular}{|c|c|c|c|}
\hline From Time & To Time & Path Name & Maximum Journey Time (m) \\
\hline $07: 45: 00$ & $07: 55: 00$ & Journey Path & 2.65 \\
\hline $07: 55: 00$ & $08: 05: 00$ & Journey Path & 3.64 \\
\hline $08: 05: 00$ & $08: 15: 00$ & Journey Path & 3.59 \\
\hline $08: 15: 00$ & $08: 25: 00$ & Journey Path & 4.34 \\
\hline $08: 25: 00$ & $08: 35: 00$ & Journey Path & 4.58 \\
\hline $08: 35: 00$ & $08: 45: 00$ & Journey Path & \\
\hline
\end{tabular}


It has been possible to compare the indicators values making the difference between the values in the two scenarios (see Tables 8, 9 and 10).

Table 8. Comparison between the two scenarios for the Route "Queue route 1"

\begin{tabular}{|c|c|c|c|c|}
\hline From Time & To Time & Route Name & ABOLUTE DIFFERENCE & DIFFERENCE \% \\
\hline 07:45:00 & 07:55:00 & Queue Route 1 & -27.81 & $-72.45 \%$ \\
\hline 07:55:00 & $08: 05: 00$ & Queue Route 1 & -26.23 & $-41.61 \%$ \\
\hline 08:05:00 & $08: 15: 00$ & Queue Route 1 & -42.91 & $-44.83 \%$ \\
\hline 08:15:00 & $08: 25: 00$ & Queue Route 1 & -92.20 & $-61.17 \%$ \\
\hline $08: 25: 00$ & $08: 35: 00$ & Queue Route 1 & -120.32 & $-66.54 \%$ \\
\hline 08:35:00 & $08: 45: 00$ & Queue Route 1 & -158.74 & $-70.36 \%$ \\
\hline
\end{tabular}

Table 9. Comparison between the two scenarios for the Route "Queue route 2"

\begin{tabular}{|c|c|c|c|c|}
\hline From Time & To Time & Route Name & ABOLUTE DIFFERENCE & DIFFERENCE \% \\
\hline 07:45:00 & $07: 55: 00$ & Queue Route 2 & -22.53 & $-64.57 \%$ \\
\hline $07: 55: 00$ & $08: 05: 00$ & Queue Route 2 & -4.85 & $-14.05 \%$ \\
\hline $08: 05: 00$ & $08: 15: 00$ & Queue Route 2 & -12.18 & $-24.91 \%$ \\
\hline $08: 15: 00$ & $08: 25: 00$ & Queue Route 2 & -31.88 & $-41.75 \%$ \\
\hline $08: 25: 00$ & $08: 35: 00$ & Queue Route 2 & -42.18 & $-54.05 \%$ \\
\hline $08: 35: 00$ & $08: 45: 00$ & Queue Route 2 & -54.05 & $-62.16 \%$ \\
\hline
\end{tabular}

Table 10. Comparison between the two scenarios for the path "Journey Path".

\begin{tabular}{|c|c|c|c|c|}
\hline From Time & To Time & Path Name & ABSOLUTE DIFFERENCE & DIFFERENCE \% \\
\hline $07: 45: 00$ & $07: 55: 00$ & Journey Path & -0.09 & $-5.18 \%$ \\
\hline $07: 55: 00$ & $08: 05: 00$ & Journey Path & -0.55 & $-17.15 \%$ \\
\hline $08: 05: 00$ & $08: 15: 00$ & Journey Path & -0.62 & $-15.51 \%$ \\
\hline $08: 15: 00$ & $08: 25: 00$ & Journey Path & -1.56 & $-30.36 \%$ \\
\hline $08: 25: 00$ & $08: 35: 00$ & Journey Path & -1.86 & $-30.04 \%$ \\
\hline $08: 35: 00$ & $08: 45: 00$ & Journey Path & -2.93 & $-39.04 \%$ \\
\hline
\end{tabular}

\section{Conclusions and Further Perspectives}

In the light of the results obtained, it has been possible to state that the activation of the LTZ in the forecourt area of Capodichino airport in Naples will contribute to the improvement of road mobility in the area itself. This will provide benefits to the users reaching the terminal. The same methodology applied for this case study can be extended and replicated to other airports in the world.

Indeed, this area will be less congested and more efficient considering that the queue lengths and the travel times will decrease. Specifically, a reduction of $72.45 \%$ of the queue length is identified for the route "Queue route 1" in the interval 7.45-7.55 as well as a reduction of $64.57 \%$ for the route "Queue route 2" in the same interval. As for the travel times, for the path "Journey Path", a reduction of $39.04 \%$ in the interval $8.35-8.45$ has been registered.
Further perspectives will consider the need of verifying, through a survey, the real travel times after the introduction of the LTZ and to compare them with our results. Moreover it will be necessary to evaluate the real distribution of cars within the parking and to compare it with the one here assumed.

\section{References}

[1] Harvey, G. (1987). Airport choice in a multiple airport region, Transportation Research A, Vol. 21, 6, 439-449.

[2] Ishii, J. Jun, S. and Dender, K. V. (2009). Air travel choices in multi-airport markets, Journal of Urban Economics, Vol. 65, 2, 216-227.

[3] Grimme, W., Berster, P. and Gelhausen, M. (2010). 
Analyses of the European air transport market - Airport Accessibility in Europe, report available at https://ec.europa.eu/transport/sites/transport/files/modes/air /studies/doc/intermodality/2010-airport-accessibility-in-eu. pdf

[4] Skinner, R. (1976). Airport choice: an Empirical Study, Transportation Engineering Journal of ASCE, Vol. 102, 4, 871-882.

[5] Sarkis, J. (2000). An analysis of the operational efficiency of major airports in the United States. Journal of Operations Management, 18, 335-351.

[6] Cascetta, E. and Pagliara, F. (2008). Integrated Railways-based Policies: The Regional Metro System project of Naples and Campania. Transport Policy, 15 (2), 81-93.

[7] Romano, E., De Riso V. and Tocchetti, A. (2000). A methodogy for air route planning: the case NAP - NYC. European Transport / Trasporti Europei VI 15, 18-28.

[8] Verbraeck, A. and Valentin, E. (2002). Simulation Building Blocks for Airport Terminal Modeling, Proceedings of the 2002 Winter Simulation Conference, 1199-1200.

[9] Hollander, Y. and Liu, R. (2008). The principles of calibrating traffic microsimulation models. Transportation, $3,347-362$.

[10] Cascetta, E. (2009). Transportation Systems Analysis: models and applications. New York: Springer. 